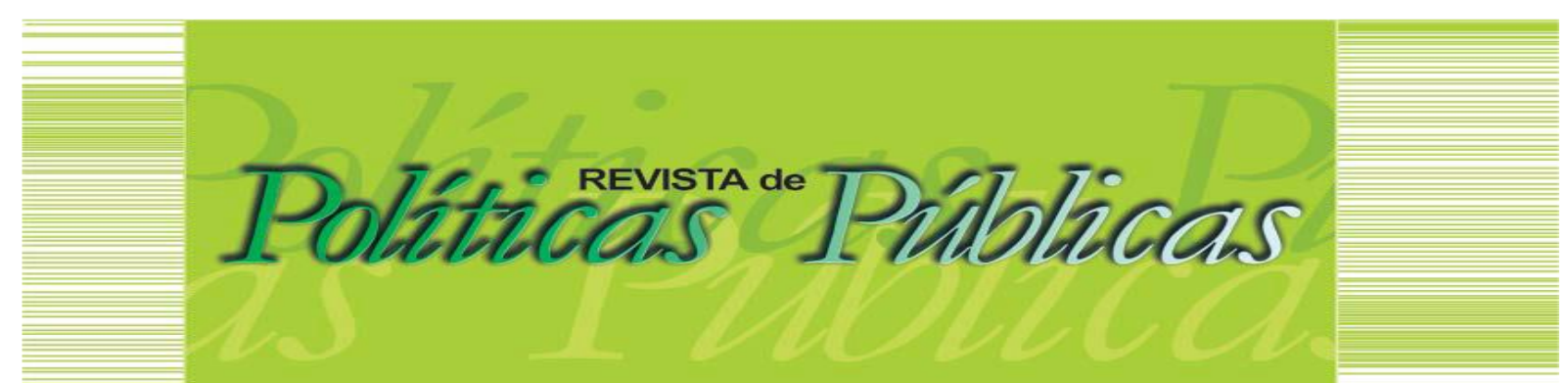

\title{
POLÍTICAS PÚBLICAS EDUCACIONAIS À LUZ DA TEORIA DA JUSTIÇA DE JOHN RAWLS
}

Rafael Soares de Lima1 Murilo Chaves Vilarinho²

\section{Resumo}

Segundo John Rawls, uma sociedade justa é aquela em que há garantia da liberdade individual e da promoção e distribuição equitativa de oportunidades e recursos. O presente artigo objetiva abordar os princípios da justiça como equidade, em Rawls, enquanto instrumentos para a reflexão acerca das políticas públicas educacionais no Brasil, em especial o Plano Nacional de Educação (PNE). Metodologicamente, o estudo se baseia em pesquisa exploratória, bibliográfica e análise documental. Como resultados, identifica correlações entre os objetivos do PNE, a manutenção das liberdades iguais e a maximização das expectativas dos menos favorecidos, bem como limitações em relação à distribuição equitativa de oportunidades de ocupação, no âmbito da estrutura básica da sociedade, com atenção especial para a educação.

Palavras-chave: Educação. Políticas Públicas. Teoria da Justiça. John Rawls.

\section{EDUCATION POLICY ACCORDING TO JOHN RAWLS' THEORY OF JUSTICE}

\section{Abstract}

According to John Rawls, a just society is one in which individual freedom and the promotion and equitable distribution of opportunities and resources are guaranteed. The present article aims to address the principles of justice as equity, in Rawls, as instruments for reflection on educational public policies in Brazil, especially the National Education Plan (PNE). Methodologically, the study is based on exploratory research, literature and document analysis. As a result, it identifies correlations between the objectives of the PNE, the maintenance of equal freedoms and the maximization of the expectations of the less fortunate, as well as limitations regarding the equitable distribution of occupation opportunities, within the basic structure of society, with special attention to the education.

Keywords: Education. Public Policies. Theory of Justice. John Rawls.

Artigo recebido em: 12/12/2020 Aprovado em: 25/05/2021 DOI: http://dx.doi.org/10.18764/2178-2865.v25n1p449-463

1 Graduado em História. Mestrando do Programa de Pós-Graduação em Administração Pública (PROFIAP), da Universidade Federal de Goiás (UFG). E-mail: rafaelsoaresdelima82@gmail.com

2 Politólogo. Doutor em Sociologia pela Universidade Federal de Goiás (UFG). Professor Adjunto e vice-coordenador do Programa de Pós-Graduação em Administração Pública (PROFIAP), da Universidade Federal de Goiás (UFG). Email: murilovilarinho@ufg.br 


\section{INTRODUÇÃO}

As democracias constitucionais modernas são conformadas por sociedades de cidadãos, com direitos fundamentais reconhecidos e protegidos, em que vigora, em tese, o Estado Democrático de Direito. Os direitos fundamentais englobam direitos de igualdade; liberdade; direitos políticos de autonomia e participação; direitos sociais, por exemplo, o direito à educação. Nesse sentido, o Estado configura-se como um ente que regula as dinâmicas sociais, segundo constado princípio da governança democrática, por intermédio de políticas públicas. Essa regulação será tanto mais justa, quanto mais o Estado garantir e salvaguardar os direitos fundamentais.

Importa, assim, não unicamente a formalidade dos direitos fundamentais, mas também a garantia desses direitos, impedindo que sejam continuamente violados. Sendo as pessoas livres enquanto indivíduos e iguais na relação social, a sociedade democrática deve ser regulada de maneira que as pessoas desfrutem da maior liberdade possivel, diante de quem exerce o poder e da maior igualdade possível entre si (BOBBIO, 1997, 2004).

No Brasil, estão inscritos na Constituição de 1988, em seu título segundo, os direitos e garantias fundamentais. Lê-se, desse modo, que são garantidos os direitos à vida, à liberdade, à igualdade, à segurança e à propriedade. São descritos como direitos sociais: a educação, a saúde, a alimentação, o trabalho, a moradia, o transporte, o lazer, a segurança, a previdência social, a proteção à maternidade e à infância e a assistência aos desamparados. São descritos também, os direitos políticos à nacionalidade, à soberania popular pelo sufrágio universal e à elegibilidade.

Diante disso, a teoria rawlsiana apresenta-se como significante instrumento de reflexão sobre a estrutura básica da sociedade. Essa estrutura pode ser compreendida como o conjunto das principais instituições políticas e sociais, que, reunidas, configuram as desigualdades sociais e econômicas e determinam a perspectiva de vida das pessoas, suas oportunidades e condições de realização de projetos de vida.

Os princípios da justiça como equidade são a garantia da liberdade individual e da promoção e distribuição equitativa de oportunidades e recursos. 0 Estado, assim, deve garantir 0 direito de cada pessoa às liberdades básicas iguais. Além disso, deve garantir que cargos e posições sejam acessíveis a todos em condições de igualdade equitativa de oportunidades, ao mesmo tempo que procura beneficiar, ao máximo, os membros menos favorecidos da sociedade (RAWLS, 2003).

A ideia de equidade é fundamental para a noção de sociedade democrática como comunidade de pessoas livres e iguais, que cooperam socialmente. Para tanto, é necessário que os indivíduos possuam um conjunto de bens primários (liberdades e oportunidades) que garantam sua 


\section{POLÍTICAS PÚBLICAS EDUCACIONAIS À LUZ DA TEORIA DA JUSTIÇA DE JOHN RAWLS}

plena participação, na sociedade democrática, como cidadãos. São cinco os tipos de bens primários: direitos e liberdades fundamentais, liberdade de movimento e livre escolha de ocupação, poderes e prerrogativas de cargos e posições de autoridade e responsabilidade, renda e riqueza e as bases sociais do autorrespeito (RAWLS, 2000, 2003).

Consequentemente, a educação encontra-se no rol das oportunidades a serem distribuídas equitativamente. Além disso, apresenta-se como condição para se possuir tais bens primários. Ademais, a importância da educação extrapola os efeitos na economia e no bem-estar social. A educação oportuniza às pessoas apreciar a cultura de suas sociedades e participar de suas atividades e práticas, sejam econômicas, políticas ou sociais. Essa capacidade de participação é a característica principal da cidadania, em que o indivíduo tem segurança de seu valor próprio (RAWLS, 1997).

No Brasil, a educação é definida pela Constituição de 1988 como um direito social fundamental. Sendo um direito de todos e dever do Estado e da família, a educação deve promover o desenvolvimento da pessoa, a formação cidadã e a qualificação para o trabalho. A Constituição estabelece como princípios do ensino, a igualdade de condições para o acesso e permanência, bem como a gestão democrática do ensino público, devendo o Estado garantir a educação básica obrigatória e gratuita, e o acesso ao Ensino Superior.

Desse modo, a teoria rawlsiana constitui-se como um parâmetro para as políticas públicas, da formulação à avaliação. Segundo o pensamento de Rawls (2003), a teoria da justiça como equidade oferece quatro contribuições práticas para uma sociedade: um caminho para lidar com diferenças políticas irreconciliáveis e a manutenção da cooperação social; um conjunto de princípios morais e filosóficos para pensar a estrutura básica da sociedade; uma maneira de refletir sobre a sociedade em seu pluralismo; e uma ponderação sobre os limites das possibilidades políticas praticáveis.

O artigo objetiva abordar os princípios da justiça como equidade, em Rawls, em sua capacidade de instrumento para a reflexão acerca das políticas públicas educacionais no Brasil, em especial o Plano Nacional de Educação (BRASIL, 2014a).

A proposta em estudo justifica-se devido à relevância da educação enquanto oportunizadora da posse dos bens primários, do acesso a posições sociais relevantes, da diminuição das disparidades sociais e da realização de projetos de vida. Além disso, a reflexão sobre a justiça das políticas públicas educacionais é, igualmente, a reflexão sobre uma sociedade justa. Rawls (2003, p. 55) procura descobrir "[...] que princípios são os mais apropriados para uma sociedade democrática que não só professa, mas pretende levar a sério a ideia de que cidadãos são livres e iguais [...]". Nesse 
sentido, a educação permite, não só o desenvolvimento de habilidades e a realização de projetos de vida, mas a realização pessoal pelo exercício de deveres sociais, também chamada de cidadania ou autorrespeito.

Em termos metodológicos e de revisão literária, esta reflexão baseou-se em pesquisa exploratória e bibliográfica, e ainda, análise documental. 0 Estado e 0 direito à educação são compreendidos segundo a teorização de Rawls $(1992,1997,2000,2003)$ e a Constituição de 1988. E as políticas públicas, como conjuntos de estratégias e decisões que objetivam modificar a vida social (SARAIVA, 2006). Com base nesse aporte teórico, analisou-se o Plano Nacional de Educação (BRASIL, 2014a), com relação à justiça dos objetivos dessa política pública.

Por fim, este artigo apresenta, primeiramente, uma abordagem sobre a Teoria da Justiça de Rawls, seguida de algumas reflexões sobre a função do Estado e o direito à educação. Em sequência, discute-se o papel das políticas públicas e analisa-se o Plano Nacional de Educação, encerrando o escrito por meio de algumas considerações finais.

\section{TEORIA DA JUSTIÇA DE RAWLS}

Rawls desenvolve sua teoria da justiça como equidade, enquanto uma concepção política da justiça. Sua aplicação é, desse modo, específica e não abrangente e metafísica. Seu objeto são as democracias constitucionais contemporâneas, que possuem origem histórica e contêm diversidade de doutrinas e pluralidade de concepções morais, por isso, uma concepção pública de justiça deve ser política. Dessa forma, o filósofo afirma que a justiça como equidade não possui pretensão de ser verdadeira em si, mas uma "[...] concepção que pode servir de base a um acordo político informado e voluntário entre cidadãos vistos como pessoas livres e iguais [...]" (RAWLS, 1992, p. 33). Assim, procura responder ao seguinte questionamento:

[...] considerando-se a sociedade como um sistema equitativo de cooperação entre cidadãos livres e iguais, que princípios de justiça são mais apropriados para determinar direitos e liberdades básicos, e para regular as desigualdades sociais e econômicas das perspectivas de vida dos cidadãos? (RAWLS, 2003, p. 58).

Baseando-se em um conjunto de ideias intuitivas fundamentais, sendo a mais importante, a ideia da sociedade como um sistema equitativo de cooperação e sua estrutura básica, a teoria da justiça como equidade procura solucionar os conflitos entre diferentes tradições democráticas. Nesse intuito, propõe dois princípios aplicáveis às instituições básicas da sociedade, para que possam realizar os valores da liberdade e da igualdade. Os dois princípios da justiça como equidade são assim descritos: 


\section{POLÍTICAS PÚBLICAS EDUCACIONAIS À LUZ DA TEORIA DA JUSTIÇA DE JOHN RAWLS}

(a) cada pessoa tem o mesmo direito irrevogável a um esquema plenamente adequado de liberdades básicas iguais que seja compatível com o mesmo esquema de liberdades para todos; e

(b) as desigualdades sociais e econômicas devem satisfazer duas condições: primeiro, devem estar vinculadas a cargos e posições acessivieis a todos em condições de igualdade equitativa de oportunidades; e, em segundo lugar, têm de beneficiar ao máximo os membros menos favorecidos da sociedade (o princípio de diferença). (RAWLS, 2003, p. 60).

As liberdades básicas iguais, de que trata o primeiro princípio de justiça como equidade, são os direitos fundamentais descritos em uma constituição e, refletem um conjunto de bens primários (liberdades e oportunidades). Já o Segundo princípio de justiça como equidade objetiva superar problemas surgidos diante da igualdade formal de oportunidades. A igualdade equitativa de oportunidades significa que aqueles que possuem semelhantes motivações, ou talentos, ou habilidades, deveriam encontrar iguais perspectivas de cultura e realização.

As desigualdades sociais e econômicas não são um problema em si, mas são injustas, quando vinculadas a dotes naturais e posições sociais. "Não merecemos o nosso lugar na distribuição de dotes inatos, assim como não merecemos nosso lugar inicial de partida na sociedade" (RAWLS, 1997, p. 111). Não há mérito, em receber dotes inatos ou em gozar de condições favoráveis para seu desenvolvimento e, se não há mérito, é injusto obter maiores benefícios e vantagens devido às habilidades inatas ou às condições familiares e sociais mais auspiciosas.

Dessa forma, não é correto que indivíduos com maiores dotes naturais, e com o caráter superior que tornou possível o seu desenvolvimento, tenham o direito a um esquema cooperativo que lhes possibilite obter ainda mais benefícios de maneiras que não contribuem para as vantagens dos outros. (RAWLS, 1997, p. 111).

A sociedade incorre em injustiça não só porque pessoas são privadas de recompensas externas geradas por cargos e posições, mas principalmente, porque essas pessoas são privadas de vivenciar a satisfação pessoal que advém do exercício das responsabilidades e compromissos sociais. Então, para ocorrer igualdade de oportunidades, a sociedade, e assim o Estado, devem favorecer aqueles com menos dotes naturais e oriundos de posições sociais menos promissoras.

Para se alcançar as finalidades da justiça como equidade, o Estado lida com a estrutura básica da sociedade, promovendo alterações para favorecer o equilíbrio equitativo e impedir a concentração excessiva da propriedade, da riqueza e do poder político. Essa estrutura básica da sociedade é o conjunto das principais instituições políticas, econômicas e sociais, que, reunidas, conformam as desigualdades sociais e econômicas. Tais desigualdades manifestam diferenças de perspectiva de vida das pessoas, pois estas verão a si mesmas de acordo com as posições que ocupam nessa estrutura e nos meios e oportunidades que têm acesso. A estrutura básica da 
sociedade, assim, circunscreve aquilo que as pessoas são e desejam ser, suas ambições e esperanças (RAWLS, 2000, 2003).

Ao mesmo tempo, a concepção de justiça como equidade tem por fundamento a noção de pessoas livres e iguais que cooperam socialmente, e que, apesar das diferenças, podem-se pôr de acordo sobre concepções políticas de justiça.

\footnotetext{
A unidade social e a lealdade dos cidadãos com respeito a suas instituições comuns não se funda em que todas sustentam a mesma concepção do bem, mas em que aceitam publicamente uma concepção política da justiça para regular a estrutura básica da sociedade.(RAWLS, 1992, p. 56).
}

As pessoas, assim consideradas, possuem capacidade de cooperar e de honrar os termos equitativos dessa cooperação, por si mesmas. São iguais, por possuírem essa capacidade mínima, e livres, por reconhecerem a si mesmas e às outras pessoas como detentoras dessa capacidade, além de serem fontes de reivindicações legítimas. $O$ conceito de pessoa é o de alguém que pode participar da vida social, e assim exercer e respeitar direitos e deveres (RAWLS, 2003).

A educação, diante disso, é tanto o desenvolvimento e treinamento de habilidades e aptidões, que permitirão realizar projetos de vida, quanto ensinamento cívico e constitucional, que sustenta o senso de cooperação e o exercício da cidadania. Dessa forma, o acesso à educação deve ocorrer de tal forma que possibilite a todos o alcance a posições sociais relevantes, e auxilie ou apoie 0 processo de aprendizagem moral dos sensos de justiça (GONDIM, 2009; ROHLING, 2015).

\section{O ESTADO E O DIREITO À EDUCAÇÃO}

Rawls não caracteriza a educação como uma das instituições básicas da sociedade, tampouco a considera como um bem primário. Assim, a princípio, as oportunidades de educação estão no rol das oportunidades a serem distribuídas equitativamente. Desse modo, a educação possui relação intrínseca com a estrutura básica da sociedade e com os bens primários.

A estrutura básica é definida como "[...] o contexto social de fundo dentro do qual as atividades de associações e indivíduos ocorrem. Uma estrutura básica justa garante 0 que denominamos de justiça de fundo" (RAWLS, 2003, p. 14). Trata-se, por exemplo, da organização política, do direito de propriedade, da estrutura econômica. Porém, alguns dispositivos são importantes, como "[...] disposições para realizar a igualdade equitativa de oportunidades na educação e em treinamentos de vários tipos" (RAWLS, 2003, p. 250). A educação se aproxima da estrutura básica da sociedade, na medida em que: 


\section{POLÍTICAS PÚBLICAS EDUCACIONAIS À LUZ DA TEORIA DA JUSTIÇA DE JOHN RAWLS}

[...] a estrutura básica está organizada de modo que inclua as instituições necessárias de justiça de fundo para que os cidadãos tenham à sua disposição os meios gerais polivalentes para treinar e educar suas capacidades básicas, e oportunidades equitativas para fazer um bom uso delas [...]. (RAWLS, 2003, p. 242).

De fato, a estrutura básica da sociedade deve garantir que todos acessem um conjunto de bens primários, vinculados a:

(I) Os direitos e liberdades básicos: as liberdades de pensamento e de consciência, e todas as demais [...].

(II) As liberdades de movimento e de livre escolha de ocupação sobre um fundo de oportunidades diversificadas, [...] que propiciam a busca de uma variedade de objetivos [...].

(III) Os poderes e prerrogativas de cargos e posições de autoridade e responsabilidade.

(IV) Renda e riqueza [...] geralmente necessários para atingir uma ampla gama de objetivos [...].

(V) As bases sociais do autorrespeito, entendidas como aqueles aspectos das instituições básicas normalmente essenciais para que os cidadãos possuam um senso vívido de seu valor enquanto pessoas e serem capazes de levar adiante seus objetivos com autoconfiança. (RAWLS, 2003, p. 82-83).

Desse modo, a estrutura básica distribui direitos e deveres básicos e, também, as vantagens provenientes da cooperação social. Para tanto, regula as contingências que afetam as perspectivas de vida dos cidadãos, e que são de três tipos:

(a) sua classe social de origem: a classe em que nasceram e se desenvolveram [...];

(b) seus talentos naturais [...] e as oportunidades que têm de desenvolver esses talentos [...];

(c) sua boa ou má sorte ao longo da vida (como são afetados pela doença ou por acidentes

[...], desemprego involuntário e declínio econômico regional). (RAWLS, 2003, p. 78).

A descrição dos tipos de bens primários e a das contingências que afetam as perspectivas de vida dos cidadãos permitem vislumbrar a importância das oportunidades educativas. Em uma sociedade em que se aplicam os princípios da justiça como equidade, "além de manter as formas habituais de despesas sociais básicas, o governo tenta assegurar oportunidades iguais de educação e cultura para pessoas semelhantemente dotadas e motivadas" (RAWLS, 1997, p. 303). Além disso, Rawls (2003, p. 231) considera que os "[...] cidadãos têm de ter um senso de justiça e as virtudes políticas que sustentam as instituições políticas e sociais justas".

No Brasil, a educação é um direito social fundamental, e a Constituição de 1988, em seu Art. 205, define como objetivos da educação, o pleno desenvolvimento da pessoa, seu preparo para o exercício da cidadania e sua qualificação para o trabalho. Entre os princípios do ensino, o Art. 206 descreve, entre outros:

I - igualdade de condições para o acesso e permanência na escola;

II - liberdade de aprender, ensinar, pesquisar e divulgar o pensamento, a arte e o saber;

III - pluralismo de ideias e de concepções pedagógicas [...]. (BRASIL, 1988). 
Ademais, ainda de acordo com a Constituição de 1988, em seu Art. 208, o Estado deve garantir a educação básica obrigatória e gratuita (educação infantil, ensino fundamental e ensino médio), o atendimento educacional especializado aos portadores de deficiência, e o acesso aos níveis mais elevados do ensino, da pesquisa e da criação artística. O Art. 210 estabelece que os conteúdos devem assegurar a formação básica comum e o respeito aos valores culturais e artísticos, nacionais e regionais. Por fim, o Art. 214 determina a elaboração do Plano Nacional de Educação, de duração decenal, com o objetivo de articular o sistema nacional de educação.

\section{POLÍTICAS PÚBLICAS À LUZ DA TEORIA DA JUSTIÇA DE RAWLS}

A justiça como equidade, enquanto concepção política de justiça, "oferece um ponto de vista publicamente reconhecido do qual todos os cidadãos podem examinar, uns perante os outros, se suas instituições políticas e sociais são justas ou não" (RAWLS, 1992, p. 32).A avaliação, segundo os princípios da justiça como equidade,transcende questões acerca da legitimidade política; pois, de fato, democracias constitucionais possuem grande legitimidade. "Ainda assim, podem não ser muito justas, ou nada justas; e igualmente suas leis e políticas" (RAWLS, 1995, p. 175, tradução nossa).

Nesse sentido, os princípios da justiça como equidade permitem não só discutir a maneira como as vantagens produzidas socialmente são distribuídas, e as condições em que as desigualdades sociais e econômicas são aceitáveis. "Toda e qualquer produção legislativa do Estado assim como eventuais atos da administração deveriam ser realizados com plena observância dos princípios [...]"da justiça como equidade (RAMOS; RIBEIRO FILHO, 2011, p. 217). Essa se constitui como um procedimento, para avaliar, segundo a justiça, o conteúdo normativo das decisões de governo, "[...] uma ferramenta para pensar [...]. Neste nível, os procedimentos políticos não são julgados apenas pela sua correção formal, mas tanto pelos valores morais que os embebem quanto por seus resultados (ARAÚJO, 2002, p. 83).

Para Rawls (1992, p. 33), "[...] o objetivo da justiça como equidade como uma concepção política é prático, e não metafísico ou epistemológico". Existem três espécies de juízos que os cidadãos devem fazer. Devem julgar "[...] que ordenações constitucionais são justas [...]", a "[...] justiça da legislação e das políticas sociais [...]", e os "[...] fundamentos e limites das obrigações e deveres políticos [...]" (RAWLS, 1997, p. 212). Dessa forma, um dos papéis dos princípios da justiça como equidade é "permitir a avaliação da justiça das políticas e fornecer orientação prática para a formulação de leis" (FREEMAN, 2007, p. 199, tradução nossa). 


\section{POLÍTICAS PÚBLICAS EDUCACIONAIS À LUZ DA TEORIA DA JUSTIÇA DE JOHN RAWLS}

O segundo princípio da justiça como equidade funciona como um guia para deliberações sobre leis e políticas sociais e econômicas. Esse princípio determina "[...] que as políticas sociais e econômicas visem maximizar as expectativas a longo prazo dos menos favorecidos, em condições de igualdade equitativa de oportunidades e obedecendo à manutenção das liberdades iguais" (RAWLS, 1997, p. 216). Para tanto, é necessário considerar uma multiplicidade de fatos sociais e econômicos, como desenvolvimento econômico, estrutura institucional, ambiente natural, entre outros. Portanto, a reflexão é feita sobre o impacto na estrutura básica da sociedade.

Compreendem-se as políticas públicas como um fluxo de decisões públicas com intuito de atuar na estrutura básica da sociedade, promovendo o equilíbrio social ou introduzindo mudanças. As políticas públicas podem ser entendidas, também, como um conjunto de estratégias ou como um sistema de decisões, para manter ou modificar a realidade de um ou vários setores da vida social. Uma política pública pode tanto definir a atuação estatal em um campo amplo de atividades, quanto atender a propósitos específicos. Também pode tratar de propósitos gerais e situações sociais desejadas, ou pode ser um conjunto de normas para setores ou problemáticas específicas (SARAIVA, 2006).

Atentando-se para os pressupostos da justiça como equidade, é possível avaliar os resultados a partir dos procedimentos e, ao mesmo tempo, os procedimentos a partir dos resultados, buscando um equilíbrio que nunca é perfeito. A justiça de um resultado é determinada pela sua contribuição para a justiça da estrutura básica, e os procedimentos são avaliados de acordo com os princípios da justiça como equidade (MESHELSKI, 2016).

Mario (2016) propõe uma avaliação que leve em conta a justiça dos propósitos, dos procedimentos e dos resultados alcançados pelas políticas públicas. Em conformidade com a concepção rawlsiana, considera-se que as políticas públicas distribuem direitos e deveres e determinam a divisão das vantagens decorrentes da cooperação social. Nessa perspectiva, sugere como questões para avaliação: quais procedimentos deveriam ser adotados frente aos objetivos e resultados pretendidos; se existem transparência e conhecimento de todos sobre esses procedimentos; se esses procedimentos promovem os resultados mais justos diante dos objetivos; e se os resultados alcançados condizem com aquilo que se entende por justo.

Assim sendo, a avaliação de políticas públicas pode ser feita unindo-se o conhecimento dos princípios da justiça como equidade e da estrutura básica da sociedade. Para julgar a justiça dos objetivos pretendidos, dos aspectos normativos, dos procedimentos utilizados e dos resultados alcançados. Para isso, é necessário que existam transparência e informações disponíveis e acessíveis. A Figura 1 ilustra essa avaliação. 
Figura1 - Avaliação de políticas públicas segundo a justiça como equidade

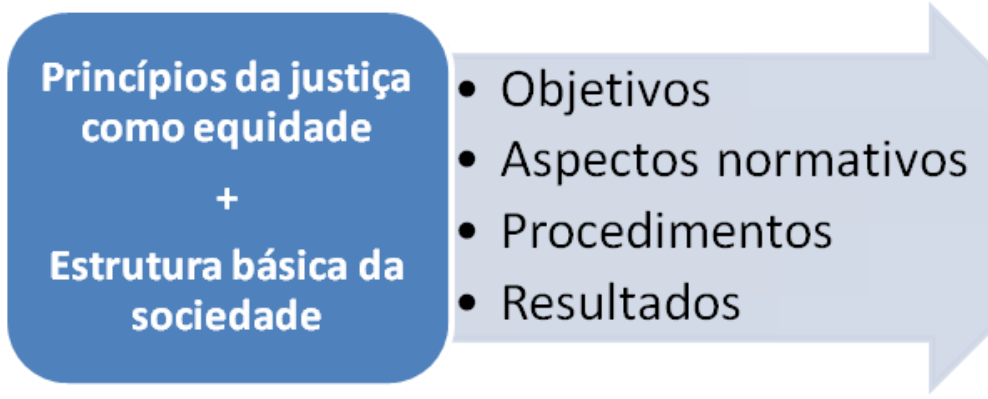

\section{Transparência}

Fonte: Elaborado pelos autores, baseado em Rawls (1997), Araújo (2002), Mario (2016) e Meshelski (2016).

Nessa avaliação, uma serie de questionamentos devem ser realizados, tendo como referência os princípios da justiça como equidade e uma multiplicidade de fatos sociais e econômicos que caracterizam a estrutura básica da sociedade. O Quadro 1 apresenta alguns questionamentos possíveis.

Quadro 1 - Questionamentos realizados na avaliação de políticas públicas

\begin{tabular}{|cl|}
\hline Elemento da política pública & \multicolumn{1}{c|}{ Questionamentos } \\
\hline & Os objetivos ferem a manutenção das liberdades básicas \\
& iguais? \\
& Os objetivos promovem o acesso equitativo a \\
& oportunidades? \\
& Os objetivos maximizam as expectativas em longo prazo \\
Objetivos & dos menos favorecidos? \\
& Que aspectos injustos da estrutura básica pretende-se \\
& modificar com os objetivos propostos? \\
\hline Os aspectos normativos facilitam ou impedem a & manutenção das liberdades básicas iguais? \\
& Os aspectos normativos facilitam ou impedem o acesso \\
& equitativo a oportunidades? \\
\hline Ospectos normativos & maximização das expectativas em longo prazo dos menos \\
favorecidos? & Os aspectos normativos levam em consideração as \\
condições sociais e econômicas dos cidadãos?
\end{tabular}




\begin{tabular}{|l} 
Os aspectos normativos facilitam ou impedem as \\
modificações desejadas na estrutura básica? \\
\hline Os procedimentos de execução da política pública facilitam \\
ou impedem a manutenção das liberdades básicas iguais? \\
Os procedimentos de execução da política pública facilitam \\
ou impedem o acesso equitativo a oportunidades? \\
Os procedimentos de execução da política pública facilitam \\
ou impedem a maximização das expectativas em longo \\
prazo dos menos favorecidos? \\
Os procedimentos de execução da política pública levam \\
em consideração as condições sociais e econômicas dos \\
cidadãos? \\
Os procedimentos de execução da política pública facilitam \\
ou impedem as modificações desejadas na estrutura \\
básica? \\
Os resultados ferem a manutenção das liberdades básicas \\
iguais? \\
Os resultados promovem o acesso equitativo a \\
oportunidades? \\
Os resultados maximizam as expectativas em longo prazo \\
dos menos favorecidos? \\
Os resultados demonstram melhorias na estrutura básica \\
da sociedade? \\
Os resultados corrigem contingências e promovem \\
situações sociais desejáveis? \\
\hline Hesuências indesejáveis observadas? \\
\hline
\end{tabular}

Fonte: Elaborado pelos autores, baseado em Rawls (1997), Araújo (2002), Mario (2016) e Meshelski (2016).

\section{O PNE À LUZ DA JUSTIÇA COMO EQUIDADE}

O Plano Nacional de Educação (PNE) é uma política pública abrangente, que abarca todos os níveis e modalidades educacionais, da educação básica (educação infantil, ensino fundamental, médio e educação profissional, técnica e tecnológica) à educação superior (graduação e pós-graduação), além de aspectos da gestão e financiamento da educação no Brasil. Em suma, é 
composto por diretrizes orientadoras, metas a serem alcançadas e estratégias a serem aplicadas no período de 2014 a 2024.

\footnotetext{
São diretrizes do PNE:

I - erradicação do analfabetismo;

II - universalização do atendimento escolar;

III - superação das desigualdades educacionais, com ênfase na promoção da cidadania e na erradicação de todas as formas de discriminação;

IV - melhoria da qualidade da educação;

$\checkmark$ - formação para o trabalho e para a cidadania, com ênfase nos valores morais e éticos em que se fundamenta a sociedade;

VI - promoção do princípio da gestão democrática da educação pública;

VII - promoção humanística, científica, cultural e tecnológica do País;

VIII - estabelecimento de meta de aplicação de recursos públicos em educação como proporção do Produto Interno Bruto - PIB, que assegure atendimento às necessidades de expansão, com padrão de qualidade e equidade;

IX - valorização dos (as) profissionais da educação;

$X$ - promoção dos princípios do respeito aos direitos humanos, à diversidade e à sustentabilidade socioambiental. (BRASIL, 2014a).
}

Suas vinte metas podem ser agrupadas em cinco grupos. As metas 1, 2, 3, 5, 6, 7, 9, $10 \mathrm{e}$ 11 tratam da garantia do direito à educação básica com qualidade. As metas 4 e 8 dizem respeito à redução das desigualdades e à valorização da diversidade. As metas 15 a 18 relacionam-se à valorização dos profissionais da educação. As metas 12 a 14 referem-se à educação superior. $E$ as metas 19 e 20 concernem à gestão democrática e financiamento da educação (BRASIL, 2014b).

As diretrizes e metas podem ser analisadas enquanto objetivos da política pública. A erradicação do analfabetismo, a universalização do atendimento escolar e a promoção dos princípios do respeito aos direitos humanos e à diversidade, demonstram a manutenção das liberdades iguais. Já a superação das desigualdades educacionais, a promoção da cidadania e a erradicação das formas de discriminação coadunam-se com a maximização das expectativas dos menos favorecidos.

Os objetivos do PNE pretendem modificar exatamente as condições de igualdade equitativa de oportunidades. Trata-se, justamente, do acesso às oportunidades de educação, com superação de desigualdades e discriminação. Ainda que, no âmbito da estrutura básica da sociedade, isso não garanta, por si mesmo, que aqueles que possuem semelhantes motivações, ou talentos, ou habilidades, encontrarão iguais perspectivas de cultura e realização, independente das contingências.

Alguns objetivos, marcadamente os que tratam da presença no sistema de ensino e do nível de aprendizado e qualidade na educação, são influenciados diretamente pela estrutura básica da sociedade em sua capacidade de regular as contingências que afetam as perspectivas de vida dos cidadãos. A teoria rawlsiana não permite supor que as oportunidades de educação, por si mesmas, promovam a superação das contingências, mas, ao contrário, a estrutura básica justa é que 


\section{POLÍTICAS PÚBLICAS EDUCACIONAIS À LUZ DA TEORIA DA JUSTIÇA DE JOHN RAWLS}

disponibiliza as condições para que as pessoas acessem meios diversos de educação e treinamento, bem como oportunidades equitativas de ocupação.

A formação para o trabalho e a cidadania, a ênfase nos valores morais e éticos em que se fundamenta a sociedade e a promoção humanística, científica, cultural e tecnológica, também correspondem às ideias rawlsianas. Tanto à noção de que os cidadãos devem possuir senso de justiça e virtudes políticas que sustentem as instituições políticas e sociais justas, quanto ao entendimento de que a educação deve oportunizar às pessoas apreciar a cultura de suas sociedades e participar de suas atividades e práticas, sejam econômicas, políticas ou sociais.

As 253 estratégias, vinculadas às vinte metas do PNE, podem ser avaliadas enquanto aspectos normativos da política pública. Para tanto seria necessário identificar se essas estratégias não conflitam com os objetivos, no sentido da manutenção das liberdades básicas iguais, acesso equitativo a oportunidades e maximização das expectativas dos menos favorecidos. Tal análise encontra-se fora do escopo deste artigo.

A análise dos procedimentos e resultados também se encontra fora do escopo deste artigo. A reflexão sobre a justiça desses dois elementos é a reflexão sobre a justiça da materialização da política pública. No caso do PNE, isso envolve a construção dos planos decenais de estados e municípios, as condições objetivas, econômicas e políticas, a regulamentação de metas e estratégias, bem como a utilização dos recursos destinados à educação (DOURADO, 2016).

Segundo o Relatório do $3^{\circ}$ ciclo de monitoramento das metas do Plano Nacional de Educação (BRASIL, 2020), o PNE alcançou em média 75\% de suas metas. Ainda assim, metas importantes provavelmente não serão alcançadas, com relação a: oferta de educação infantil; conclusão do ensino fundamental na idade correta; universalização do ensino médio; atendimento educacional especializado; nível de aprendizado e qualidade na educação básica; oferta de educação em tempo integral; escolaridade de populações menos favorecidas; oferta de educação profissional e tecnológica; presença de jovens de 18 a 24 anos no ensino superior; títulos de doutorado anuais; formação, rendimento e condições de trabalho de docentes; gestão democrática; e investimento público em educação pública.

Por fim, com relação à transparência, há grande quantidade de informações disponíveis sobre o PNE. O Plano indica como referências de dados, a Pesquisa Nacional por Amostra de Domicílios (PNAD), o censo demográfico e os censos nacionais da educação básica e superior. Além disso, são designados para monitoramento e avaliações periódicas, o Ministério da Educação (MEC), a Comissão de Educação da Câmara dos Deputados, a Comissão de Educação, Cultura e Esporte do 
Senado Federal, o Conselho Nacional de Educação (CNE) e o Fórum Nacional de Educação. Todas essas instâncias publicaram obras diversas sobre o PNE, com disponibilidade de consulta via internet.

\section{CONCLUSÃO}

Demonstrou-se que a Teoria da Justiça como equidade, de John Rawls, constitui instrumento prático para a reflexão sobre políticas públicas educacionais. Utilizando-se o conhecimento dos princípios da justiça como equidade e da estrutura básica da sociedade, pode-se julgar a justiça dos objetivos pretendidos, dos aspectos normativos, dos procedimentos utilizados e dos resultados alcançados por uma política pública.

Analisou-se o PNE com relação aos seus objetivos, entrevistos na descrição das diretrizes e metas do Plano. Encontraram-se correlações entre os objetivos e a manutenção das liberdades iguais, bem como a maximização das expectativas dos menos favorecidos. Identificaram-se as limitações com relação à distribuição equitativa de oportunidades de ocupação, no âmbito da estrutura básica da sociedade, já que as oportunidades educacionais não proporcionam, por si mesmas, a superação das contingências que afetam as perspectivas de vida dos cidadãos.

O estudo limitou-se a analisar os objetivos do PNE, portanto, estudos futuros poderiam debruçar-se sobre os aspectos normativos, os procedimentos e os resultados da política pública. A avaliação de políticas públicas, fundamentada na teoria da justiça como equidade, permite identificar seus efeitos na estrutura básica e na promoção de uma sociedade de cidadãos livres e iguais que cooperam entre si.

\section{REFERÊNCIAS}

ARAÚJO, C. Legitimidade, justiça e democracia: o novo contratualismo de Rawls. Lua Nova, n. 57, p. 73-85, 2002.

BOBBIO, N. Igualdade e liberdade. Rio de Janeiro: Ediouro, 1997.

A era dos direitos. Rio de Janeiro: Elsevier, 2004.

BRASIL. Constituição da República Federativa do Brasil de 1988. Disponível em:

http://www.planalto.gov.br/ccivil_03/constituicao/constituicaocompilado.htm. Acesso em: 20 mar. 2020.

Lei n 13.005, de 25 de junho de 2014. Aprova o Plano Nacional de Educação - PNE e dá outras providências. Brasília, 2014. 
Ministério da Educação. Planejando a próxima década: conhecendo as 20 metas do Plano Nacional de Educação. 2014. Disponível em:

http://pne.mec.gov.br/images/pdf/pne_conhecendo_20_metas.pdf. Acesso em: 23 nov. 2020.

. Instituto Nacional de Estudos e Pesquisas Educacionais Anísio Teixeira (Inep). Relatório do

$3^{\circ}$ ciclo de monitoramento das metas do Plano Nacional de Educação - 2020: sumário executivo. Brasília: INEP, 2020.

DOURADO, L. F. Plano Nacional de Educação: política de Estado para a educação brasileira. Brasília: INEP, 2016.

FREEMAN, S. Rawls. New York: Routledge, 2007.

GONDIM, E. John Rawls: o papel da educação. Revista Filosofia Capital, v. 4, n. 9, p. 56-68, 2009.

MARIO, C. G. de. Concepções de justiça e a análise de políticas públicas.Administração Pública e Gestão Social, v. 8, n. 1, p. 5-14, jan./mar. 2016.

MESHELSKI, K. Procedural justice andaffirmativeaction. EthicalTheoryand Moral Practice, v. 19, n. 2, p. 425-443, feb./nov. 2016.

RAMOS, P. R. B.; RIBEIRO FILHO, J.L. O ideal de justiça política e constituição em John Rawls: Análise dos pontos principais da "teoria da justiça como equidade". Revista de Informação Legislativa, v. 48, n. 189, p. 211-225, 2011.

RAWLS, J. Justiça como equidade: uma concepção política, não metafísica. Lua Nova, n. 25, p. 25-59, 1992. 1995.

Politicalliberalism: replytoHabermas. The Journal of Philosophy, v. 92, n. 3, p. 132-180, mar.

Uma teoria da justiça. São Paulo: Martins Fontes, 1997.

O liberalismo político. São Paulo: Editora Ática, 2000.

. Justiça como equidade: uma reformulação. São Paulo: Martins Fontes, 2003.

ROHLING, M. Sobre a educação a partir de "Atheoryof justice": entre bens primários, igualdade equitativa de oportunidades e reciprocidade. Saberes, Natal, v. 1, n. 11, p. 5-20, fev. 2015.

SARAIVA, E. Introdução à teoria da política pública. In: SARAIVA, E.; FERRAREZI, E. Políticas públicas: coletânea v. 1. Brasília: ENAP, 2006. p. 21-42. 